\title{
Innovative aspects in developing bridge monitoring systems
}

\author{
Andrey Yashnov ${ }^{1, *}$, and Pavel Kuzmenkov ${ }^{1}$ \\ ${ }^{1}$ Siberian Transport University, 630049 Novosibirsk, Russia
}

\begin{abstract}
The average age of bridges in operation and their accumulated damage are ever increasing, while design solutions of new bridges are increasingly complex. It is difficult to adequately reflect performance characteristics of these structures in design models. In order to prevent accidents during construction and operation, it is necessary to verify experimentally that the actual stress-strain behavior corresponds to design parameters. Special monitoring systems are developed and implemented to improve the operational reliability of structures. This study uses mathematical modeling and instrumental measurements to develop monitoring systems. A systematic approach has been implemented. The paper presents the results produced by modern automated measuring, recording and data processing equipment to provide online diagnostics and long-term status monitoring of bridge structures.
\end{abstract}

\section{Introduction}

In recent years, the road transportation of passengers and goods has been growing very fast. It is the most popular mode of transportation, accounting for more than $50 \%$ of the total traffic. Traffic speed and intensity, as well as cargo-carrying capacity of new cars and trucks are ever increasing. Rail transport accounts for $45 \%$ of the total freight turnover in Russia. On June 1, 2017, Russian Railways put high-capacity rolling stock (27 tonnes per axle) into pilot operation. The company also plans to continue increasing loads up to 30 tonnes per axle.

On the one hand, the average age of road and rail bridges in operation is increasing, as well as the number of damages accumulated during operation. There is a growing need for early detection of a tendency towards performance degradation in each particular structure. Automated monitoring is proposed as an innovative method [1-7]. On the other hand, new bridge construction is characterized by increasingly complex structures for bridging large spans and the introduction of poorly studied advanced materials, such as polymer composites, in designing new structures [8-11]. Therefore, new bridges also require automated monitoring.

The primary purpose of the proposed innovations is to increase the operational safety and maintenance efficiency of bridge structures on the basis of automated diagnostics and status monitoring. Taking into account the high cost of automated monitoring tools, it is

* Corresponding author: $\underline{\text { yan } @ \text { stu.ru }}$ 
necessary to select a minimum set of parameters that provide maximum information about the technical condition. The number of controlled parameters can be expanded without increasing the cost of the monitoring system, through periodic automated measurements [12]. All necessary parameters are recorded at certain intervals, rather than simultaneously. Excessive and insufficient information may reduce the efficiency of monitoring.

\section{Research methodology}

To illustrate the proposed approach, let us consider implementing periodic automated monitoring of tension strains of cable elements in a network arch (Fig. 1a). In parallel with periodic monitoring, a continuous automated monitoring station has been created (Fig. 1b) for continuous monitoring of integral parameters that reflect the overall technical condition of the structure. These controlled parameters are likely to include natural oscillation frequencies, movements of a reference point, stresses in the cross section of a structure that has the lowest capacity margin, etc. The continuous monitoring station can be used to determine stresses in cables, including invariant values and values independent of temporary loads.

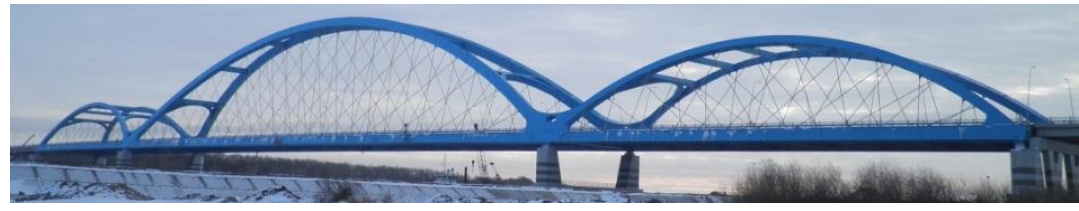

a

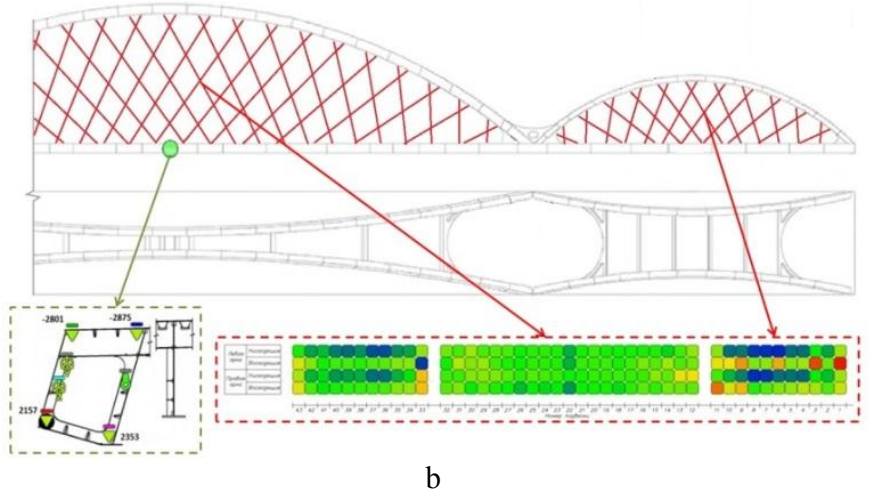

Fig. 1. Implementation of periodic automated monitoring: a - general view of a span structure; $b$ schematic diagram of the monitoring system.

The obtained values of stresses in cables can be conveniently represented as a color "digital portrait" [13] (Fig. 1b), where each strain value is marked with its own display color: green means no difference from calculated values; a red gradient indicates that the actual strain exceeds a design one; a blue gradient indicates a loss of tension. Periodic automated measurements with generation, comparison and analysis of "digital portraits" will make it possible to predict possible negative tendencies in the current state of structures. Thus, the primary objective of monitoring — to prevent limit states by taking preventive measures, rather than simply record their development — will be accomplished.

In order to ensure the correct operation of the monitoring system, it is necessary to implement it during construction. Information on the initial state of a structure will serve as the basis for a correct interpretation of field evidence. For example, control measurements 
may suggest there is some sagging of the structure, but it is impossible to make a correct conclusion without knowing its initial state. Or there may be another situation: a controlled element of the structure is subject to stresses from temporary loads that are much lower than the design resistance. However, there are load-induced cracks in this structure. These "inverse" problems can be solved by using modern automated instrumentation systems and software packages for calculating bridge structures. It is required to create a calculated finite element model that adequately reflects the actual operation of a bridge structure. For this purpose, it is necessary to conduct a cycle of measurements of stress-strain states under constant test load, and then adapt the developed model to test results.

\section{Experimental data and results}

Based on tests of a combined metal span structure, namely a continuous stiffening truss with a flexible arch and arched saddles (Fig. 2a), the developed finite element model was tested. The obtained actual stresses (Figs. $2 \mathrm{~b}$ and $2 \mathrm{c}$ ) confirm the adequacy of this model, which makes it possible to use it in numerical experiments.

Calculations and experimental studies of the stress-strain state performed on the basis of periodical monitoring provided the following results. Even under constant loads only, the level of stresses in short hangers (B1) is close to the design resistance of the metal. The existing vehicle loads were likely to lead to cracking, which actually occurred in the initial period of operation. The cracking process and the formation of an actual hinge at the point where the hanger B1 is attached to the arch is followed by redistribution of strains and increasing stresses in the nearest columns (H12). In general, however, the redistribution of strains does not create additional stress raisers. The hanger B1 will work as an element hinged to the arch and, therefore, have almost no bending moments and related stresses that can cause cracking. The total stresses in short columns also do not exceed the design resistances. At this stage, the structure is in a stable state, but we have identified some elements that may be subject to cracking. These findings will serve as the basis for making decisions relating to repairs of damaged elements and periodic control measurements of stress-strain states of structural elements.

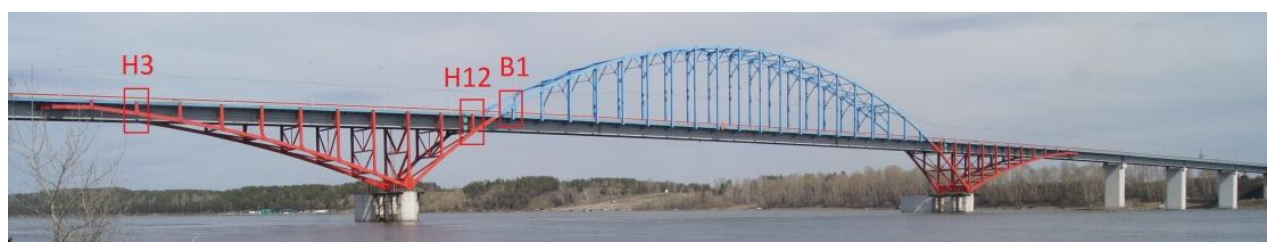

a

Actual stress level Design stress level

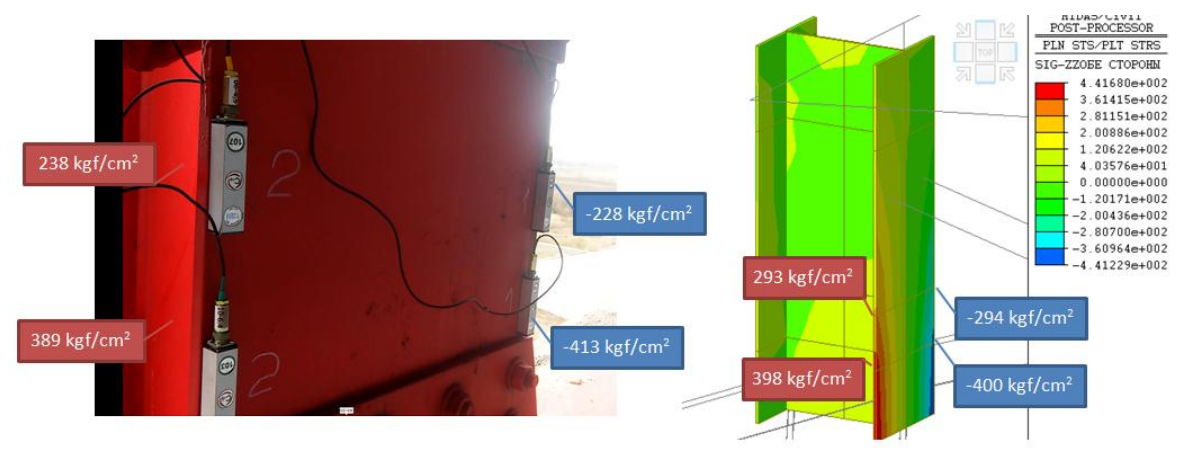


Actual crack width

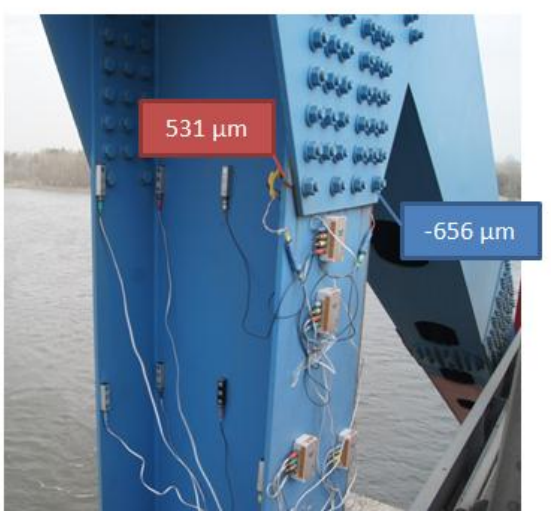

Design crack width

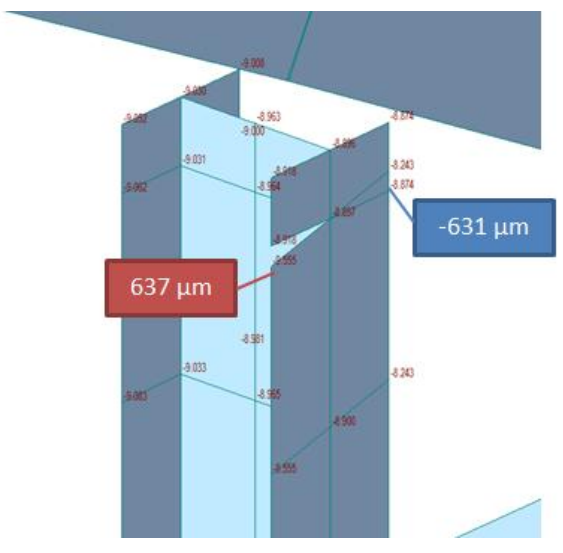

$\mathrm{c}$

Fig. 2. Periodic automated monitoring: $\mathrm{a}$ - general view of the bridge span structure; $\mathrm{b}$ - performance of the column $\mathrm{H} 3$ under test load; $\mathrm{c}$ - performance of the hanger B1 under test load.

\section{Conclusion}

The findings of these studies confirm the possibility of increasing the operational safety and maintenance efficiency of bridge structures using innovative diagnostics and monitoring techniques. The studies are of practical significance because they demonstrate the possibility of using the developed methods and techniques for automated diagnostics and monitoring of stress-strain states in bridge maintenance systems.

\section{References}

1. J.J. Moughty, J.R. Casas, Applied Sciences, 7(5), 510 (2017).

2. A.C. Neves, I. Gonzalez, J. Leander, R. Karoumi, Journal Civil Stract Health Monitoring, 689-702 (2017).

3. Ch. Tan, A. Elhattab, N. Uddin, Journal Civil Stract Health Monitoring, 615-625 (2017).

4. H.W. Shih, D.P. Thambiratnam, T.H.T. Chan, Structural Control and Health Monitoring, 20, 1271-1290 (2013).

5. T.M. Baranov, Thesis of Candidate of technical sciences, Irkutsk State Transport University, Irkutsk (2014). (in Russian)

6. VCE Vienna Consulting Engineers ZT GmbH, Life Cylce Management, available at: http://www.brimos.com/BRIMOS/HTML/en/services/lca.html (June 20, 2018).

7. Roctest, Our applications, available at: https://roctest.com/en/product-applications/ (June 20, 2018).

8. A.N. Ivanov, P.Yu. Kuzmenkov, Siberian Transport University Bulletin, 2 (2016). (in Russian)

9. A.N. Ivanov, B.V. Pyrinov, A.N. Yashnov, Eksperimental'nye issledovanija gibridnogo proletnogo stroenija [Experimental studies of a hybrid span structure] (Saarbrucken: LAP LAMBERT Academic Publishing, 2014). (in Russian)

10. A.N. Ivanov, E.A. Kuzmitskaya, Proceedings of the International scientific and practice conference (2016). (in Russian)

11. A.N. Ivanov, A.V. Martynov, Simvol nauki [Science Symbol], 6 (2015). (in Russian) 
12. A.N. Jashnov, P.Yu. Kuzmenkov, Transport infrastructure of the Siberian region, Proceedings of the $7^{\text {th }}$ International scientific conference (Irkutsk, 2016). (in Russian)

13. A.N. Yashnov, I.I. Snezhkov, S.L. Odnorog, P.Yu. Kuzmenkov, Certificate of official registration of computer programs No. 2017618579 (2017). (in Russian) 